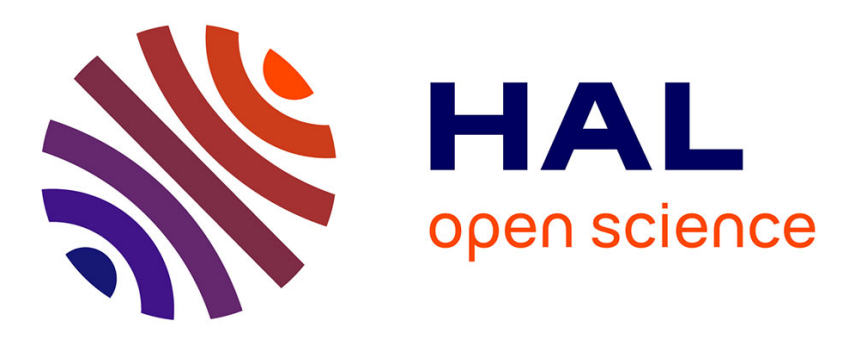

\title{
Modeling Industrial Symbiosis Using Design Structure Matrices
}

Andreas Makoto Hein, Marija Jankovic, Romain Farel, Lei I Sam, Bernard Yannou

\section{- To cite this version:}

Andreas Makoto Hein, Marija Jankovic, Romain Farel, Lei I Sam, Bernard Yannou. Modeling Industrial Symbiosis Using Design Structure Matrices. 17 th INTERNATIONAL DEPENDENCY AND STRUCTURE MODELING CONFERENCE, DSM 2015, Nov 2015, Fort Worth, United States. hal01270870

\section{HAL Id: hal-01270870 \\ https://hal.science/hal-01270870}

Submitted on 8 Feb 2016

HAL is a multi-disciplinary open access archive for the deposit and dissemination of scientific research documents, whether they are published or not. The documents may come from teaching and research institutions in France or abroad, or from public or private research centers.
L'archive ouverte pluridisciplinaire HAL, est destinée au dépôt et à la diffusion de documents scientifiques de niveau recherche, publiés ou non, émanant des établissements d'enseignement et de recherche français ou étrangers, des laboratoires publics ou privés. 
See discussions, stats, and author profiles for this publication at:

https://www.researchgate.net/publication/281284096

\section{Modeling Industrial Symbiosis Using Design Structure Matrices}

CONFERENCE PAPER · NOVEMBER 2015

READS

108

5 AUTHORS, INCLUDING:

Andreas M. Hein

Université Paris-Saclay

28 PUBLICATIONS 30 CITATIONS

SEE PROFILE

Bernard Yannou

Ecole Centrale Paris

351 PUBLICATIONS 879 CITATIONS

SEE PROFILE 


\title{
Modeling Industrial Symbiosis Using Design Structure Matrices
}

\author{
Andreas M. Hein ${ }^{1}$, Marija Jankovic ${ }^{2}$, Romain Farel $^{3}$, I Sam $\mathrm{Lei}^{4}$, Bernard Yannou ${ }^{5}$ \\ 1,2,5 CentraleSupélec / Laboratoire Genie Industriel \\ 1,3,4,5 Paris-Saclay Energy Efficiency (PS2E)
}

\begin{abstract}
Today, industry is under constant pressure to increase competitiveness and resource-efficiency. One possibility to cope with these challenges is industrial symbiosis. Industrial symbiosis is based on substituting a new resource by an undervalued resource such as waste. Thereby, industrial symbiosis reduces waste and saves resources. One of the practical challenges in developing industrial symbioses is the identification of symbiosis opportunities. In particular, the question how "new resource - substitute" combinations can be identified has not yet been addressed in the literature. This paper presents a modeling approach for industrial symbioses in industrial parks, based on design structure matrices (DSM), which intends to support the identification of substitution opportunities. The approach is applied to a sample industrial park. Combined with an optimization algorithm, the symbiosis model is used for identifying not only symbiosis opportunities but also the most attractive combination(s) of symbioses within the industrial park.
\end{abstract}

Keywords: Industrial ecology, industrial symbiosis, eco-industrial park, systems architecture, DSM

\section{Introduction}

An industrial symbiosis can be defined as "a flow of underutilised resource(s) (comprising substances and/or objects and/or energy), from an entity which would otherwise discard them, to another entity which uses them as a substitute for new resources." (Deutz, 2014) An example for an industrial symbiosis is the use of waste water from a refinery as cooling water in a power plant for steam generation, depicted in Fig.1. Without the symbiosis the power plant would use surface water from a lake. The refinery saves the cost of constructing waste water treatment facilities. The underutilized resource is therefore waste water. Without the symbiosis, it would be discarded and not further used. The power plant would use a new resource, which is the lake water. By establishing an industrial symbiosis, both symbiosis partners save cost and resources.
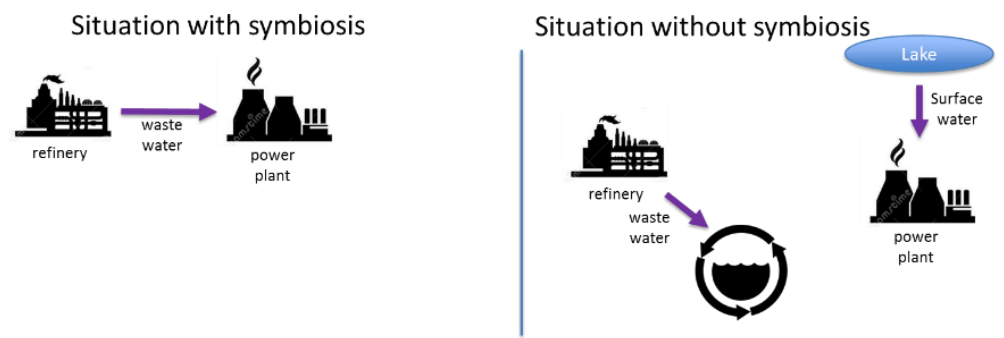

Fig. 1: Waste water-based symbiosis at Kalundborg 
Industrial symbioses play an important role in eco-industrial parks. An eco-industrial park is a set of businesses that share resources in order to increase profitability and reduce environmental impact (Lowe, 2001). The most famous eco-industrial park is located at Kalundborg in Denmark. Over 40 different symbioses have reduced $\mathrm{CO} 2$ emission by about $8 \%$ and are saving three million tons of water per year (Chertow, M. R., Lombardi, 2005; Hodge et al., 2010; Jacobsen, 2006; Korhonen and Snäkin, 2005; Sokka, 2011; Tian and Zelkowitz, 1992). The waste water symbiosis in Fig. 1 is an existing symbiosis within the Kalundborg eco-industrial park.

One of the challenges in defining an industrial symbiosis is to find options for with whom to form a symbiosis and what resource to exchange. Most of the existing literature focuses on how to optimize already identified industrial symbioses within an eco-industrial park or their process engineering aspects (Cao, Kai, Feng Xiao, \& Wan, 2009; Gu, C., Leveneur, S., Estel, L., Yassine, 2013; Kim et al., 2010; Maillé, M., \& Frayret, 2013; Monteiro et al., 2010; Schulze, 2014).

Existing approaches for identifying potential industrial symbioses have focused on the inputs and outputs of industrial plants (Chertow, 2000; Schulze, 2014). Inputs and outputs of the same type are matched. However, input / output matching is only capable of identifying obvious symbiosis opportunities where the type of input and output are identical, e.g. output: gypsum, input: gypsum. This approach would miss opportunities such as the aforementioned waste water symbiosis. In that case, fresh water is substituted by waste water. Finding proper substitutes is a non-trivial problem, as fresh water cannot be replaced by waste water in general but only under specific circumstances.

This paper addresses the non-trivial case of finding industrial symbiosis opportunities based on substitution by using design structure matrices (DSMs).

In the following, first, a terminology for designing industrial symbiosis is developed. Key concepts such as different concretization levels of symbioses and types of substitution are defined. The symbiosis DSM model is then based on these concepts. Finally, a methodology for identifying symbiosis opportunities and the optimal combination(s) of symbioses on a territory are presented.

\section{Modeling Industrial Symbiosis with DSMs}

DSMs have been used for numerous applications such as modeling the architecture of systems (component - component DSM), processes within organizations (process DSM), relationships between parameters (parametric DSM), organizational capabilities (capability DSM), and component reuse (heritage DSM) (Browning and Eppinger, 2002; Browning, 2001; Hein, 2014; Hein et al., 2014, 2012; Pektaş and Pultar, 2009).

In this paper, DSMs are applied to identifying industrial symbiosis opportunities. What elements of a symbiosis need to be represented in a DSM? From a physical viewpoint, industrial symbioses include at least one material and energy flow. This physical viewpoint of industrial systems pertains to the concept of an "industrial ecosystem". In industrial ecosystems, industrial actors exchange material and energy flows, analogous to natural ecosystems (Haberl, 2001). The industrial ecosystem view extends the classic perspective of economics as a transfer of goods / money. It focuses on the physical basis of economic transactions such as resource consumption and waste creation. Leontief has 
developed matrix-based model for industrial activities and has proposed a model that maps the classical economic perspective to the industrial eco-system perspective (Leontief, 1986, 1970). In this paper, we limit the model to the material and energy flows that are associated with symbiosis opportunities and not material and energy flows in general.

\subsection{Modeling Industrial Symbiosis}

For modeling industrial symbioses with DSMs, we need to develop a terminology for describing an industrial symbiosis (Hein et al., 2015). We use the following statements as a baseline:

- $\quad$ An industrial symbiosis includes at least one material / energy flow.

- The material / energy flow is an underutilized resource supplied by one symbiosis partner. This symbiosis partner is called "supplier".

- The symbiosis partner that uses the resource as a substitute is called "receiver".

- Symbiosis partners can have different roles in different symbioses. A partner can be a receiver in symbiosis A and a supplier in symbiosis B.

- The material / energy flow is transferred from the supplier to the receiver. In addition, it may be converted.

- A set of industrial symbioses within an industrial park is called a symbiosis network.

We use the following limitations for facilitating the development of an initial DSM model:

- Symbioses with a single material / energy flow.

- $\quad$ Flows are only transferred but not transformed.

After having defined the terminology and limitations, steps in defining industrial symbioses are presented next.

\subsection{Symbiosis concretization stages}

For identifying industrial symbioses systematically, different levels of concretization are defined, analogous to design process steps in classic product development (Otto and Wood, 2000; Pahl et al., 2007). Fig. 3 provides an overview of the concretization levels.

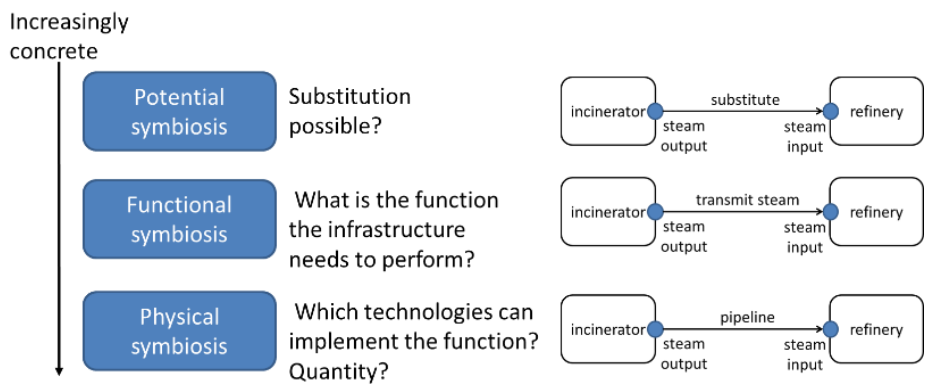

Fig. 3: Levels of concretization of industrial symbiosis

\section{Potential symbiosis}

A potential symbiosis exists when there is a potential supplier that is able to offer an underutilized resource and there is another potential receiver that has a demand for the resource as a substitute for a new resource. 
At this point, it is necessary to clarify the notion of "substitute". In its original sense, a substitute is a replacement for something. The replacement is not necessarily identical with the thing being replaced. To account for this distinction, we propose the following types of substitutes:

- Identical: A substitute is identical if it is indistinguishable from the original resource in its composition and can be used as an input for the same function(s), e.g. a boiler has the function to heat water and can use natural gas as an input. The existing supplier for natural gas can be substituted by natural gas from a different supplier. Fig. 3 shows an example where steam is substituted by steam.

- Functional substitute: The substitute differs from the original resource in its composition but can be used as an input to the same function. For example, methane from biomass may substitute natural gas for producing steam in a boiler (function: produce steam). Due to the difference in composition, there might be compatibility issues with using the substitute such as lower performance or degradation of equipment.

Note that substitution is not limited to a plant's inputs and outputs. Only taking inputs and outputs into consideration misses opportunities for symbioses that are based on energy / material flows within a plant. For example, steam is generated within a plant by a boiler. The boiler is fueled by natural gas. Two substitutions are possible. First, the natural gas (an input to the plant) can be substituted, e.g. by methane. This symbiosis opportunity could be detected by looking at the input of the plant. Second, external steam can be used, replacing the boiler. This symbiosis can only be detected when information about the generation of steam within the plant is available.

\section{Functional symbiosis}

A functional symbiosis is a symbiosis where the infrastructure for transferring / converting / storing the resource is defined on a functional level, i.e. the inputs and outputs and the transformation are specified. To use a standardized way to describe functions, the "functional basis" is used, which is presented in (Hirtz, J., Stone, R. B., McAdams, D. A., Szykman, S., \& Wood, 2002; Stone, R. B., \& Wood, 2000). Fig. 3 shows an example where steam is transmitted by the symbiosis infrastructure. As mentioned before, this paper only deals with the case of transferring a resource, which includes the transmission of energy and the transportation of material.

\section{Technological symbiosis}

The technological symbiosis is a symbiosis where the infrastructure for transferring / converting / storing the resource is defined at a technological level. This means that the working principles of the technology and fundamental design data such as length of a pipeline are defined, allowing for a high-level economic feasibility analysis (Pahl et al., 2007). Fig. 3 shows an example where a pipeline is used for transmitting steam. 


\subsection{Multigraphs with ports and DSM}

The formal representation of industrial symbiosis is firmly grounded in classic graph theory and the more recent concept of multigraphs with ports (Andrei and Kirchner, 2008; Andrei, 2008; Bondy and Murty, 1976; Bretto et al., 2012). The symbiosis DSM is a view created from this formal representation.

A directed multigraph with ports extends a directed multigraph by the concept of "ports". The concept was introduced in a formal manner by (Andrei and Kirchner, 2008; Andrei, 2008). Ports are explicit connection points that are associated with nodes. Edges attach to ports. Ports can be used to represent interfaces. Interfaces are relevant for biological and artificial systems. In (Andrei, 2008), ports were used for modeling attachment points for proteins and interfaces between elements of an autonomic system. An example for a directed multigraph with ports is shown in Fig 4. The nodes and ports have "types" associated with them such as A, B, and C for nodes and a, b, c, d, and e for ports. 1, 2, 3, 4 are unique identifiers for the nodes. Multiple edges can attach to a port.

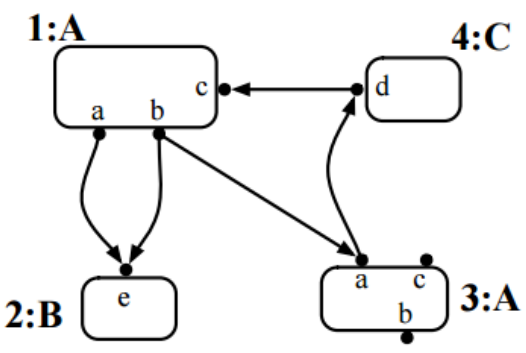

Fig. 4: Sample directed multigraph with ports from (Andrei and Kirchner, 2008)

For modeling industrial symbioses with multigraphs with ports, the following elements are added to the original definition:

- $\quad$ A port type can be assigned multiple times to a node, e.g. multiple steam ports.

- Labels "supply" and "demand" can be assigned to each port, abbreviated as " $s$ " and " $d$ ". A supply port can only have outgoing edges and a receiver port only ingoing edges.

Grounded in formal graph theory, the different DSMs are created from multigraphs with ports where the rows in the DSM represent supply ports and the columns receiver ports.

\subsection{Modeling symbioses as directed multigraphs with ports}

Table 1 shows the mapping between the elements of a multigraph with ports and different symbiosis concretization levels. Nodes represent industrial actors such as industrial plants, urban areas, and agricultural businesses. Ports can represent a potential resource supply $a$ and a resource demand $b$. At this level, supply and demand does not need to be a physical in- or output of an industrial actor. By contrast, for the functional and technological symbiosis, we assume that there is a physical input or output port of the actor that allows for a transfer of the resource, e.g. sulfur entering into the actor. In this case, $b$ is no longer the resource substituted but the resource $a$ after the transfer. 
Table 1: Multigraph with ports for modeling different symbiosis concretization levels

\begin{tabular}{|l|l|l|l|}
\hline $\begin{array}{l}\text { Multigraph with } \\
\text { port element }\end{array}$ & Potential symbiosis & $\begin{array}{l}\text { Functional } \\
\text { symbiosis }\end{array}$ & $\begin{array}{l}\text { Technological } \\
\text { symbiosis }\end{array}$ \\
\hline Node & Industrial actor & Industrial actor & Industrial actor \\
\hline Port & $\begin{array}{l}\text { Potential supply } \\
\text { resource type } a, \\
\text { demand resource } \\
\text { type } b\end{array}$ & $\begin{array}{l}\text { Physical output } a \text { or } \\
\text { input } b \text { of industrial } \\
\text { actor }\end{array}$ & $\begin{array}{l}\text { Physical output } a \text { or } \\
\text { input } b \text { of industrial } \\
\text { actor }\end{array}$ \\
\hline Edge & $\begin{array}{l}\text { Supply resource } \\
\text { temanded resource } \\
\text { type } b\end{array}$ & $\begin{array}{l}\text { Output } a \text { is } \\
\text { transferred to input } b \\
\text { by function } \\
\text { "transfer" is }\end{array}$ & $\begin{array}{l}\text { Output } a \text { insferred to input } b \\
\text { by technology x }\end{array}$ \\
\hline
\end{tabular}

Fig. 5 depicts an example symbiosis DSM with two potential symbioses. The edge (supply $a$, demand $a$ ) is a trivial match between a supply of resource $a$ and a demand for $a$. A functional symbiosis opportunity (supply $b$, demand $d$ ) exists between supply $b$ and demand $d$. The matrix diagonal is colored in grey in order to indicate that supply and demand for the same plant cannot be matched.

\begin{tabular}{|l|l|l|l|l|l|}
\hline & \multicolumn{3}{|c|}{ Actor 1:actor type A } & \multicolumn{2}{l|}{ Actor 2:actor type B } \\
\hline \multirow{2}{*}{$\begin{array}{l}\text { Actor 1: actor } \\
\text { type A }\end{array}$} & & $\begin{array}{l}\text { 1d: Demand } \\
\mathrm{d}\end{array}$ & $\begin{array}{l}\text { 2d: Demand } \\
\mathrm{e}\end{array}$ & $\begin{array}{l}\text { 3d: Demand } \\
\mathrm{a}\end{array}$ & $\begin{array}{l}\text { 4d: Demand } \\
\mathrm{g}\end{array}$ \\
\cline { 2 - 6 } & 1s: Supply a & & & Identical & \\
\hline $\begin{array}{l}\text { Actor 2: actor } \\
\text { type B }\end{array}$ & 2s: Supply b & Functional & & & \\
\cline { 2 - 6 } & 3s: Supply c & & & & \\
\hline
\end{tabular}

Fig.5: Example DSM for mapping supply resources to demand resources

\section{Application example}

The modeling approach is applied to a sample industrial park, based on an existing industrial park in France. The case consists of four industrial plants: a refinery, a toxic waste incinerator, a pharmaceutical plant, and a biomass incinerator. The supply and demand values for the plants have been modified but resemble typical values for these types of plants. Do industrial symbiosis opportunities exist in this industrial park? If yes, which combination of symbioses is most attractive from an economic and environmental point of view? Commonly, detailed data for plant inputs, outputs, and internal processes are confidential. Hence, the analysis has to start with a priori assumptions and estimates. A schematic aerial view of the industrial park is shown in Fig. 6.

The following steps are performed in order to identify potential symbioses and to find the best combination of symbioses:

1. Create potential symbiosis DSM and identify substitution opportunities.

2. Solve the supply / demand allocation problem by using an optimization algorithm. 


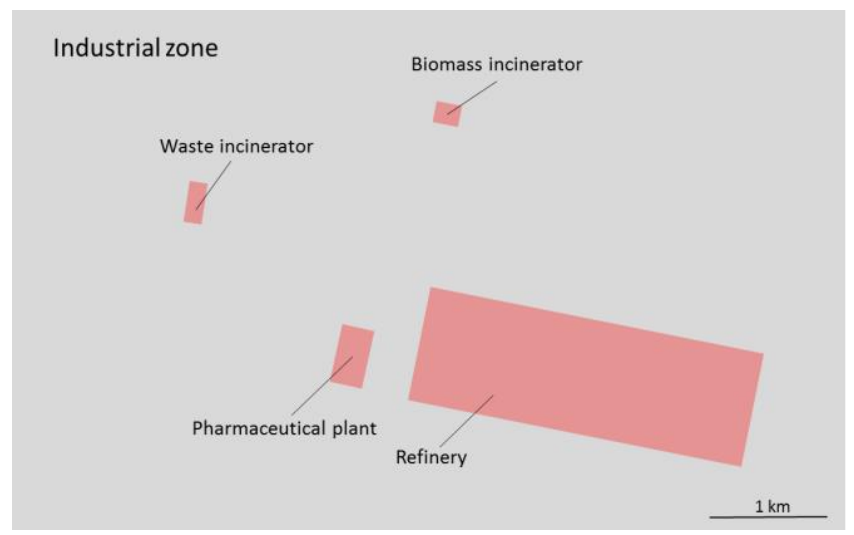

Fig.6: Schematic aerial view of a fictive industrial park

Fig. 7 shows a section of the potential symbiosis DSM for the industrial park. The DSM was created by listing all in- and outputs of plants, major intermediate resource flows within the plants, and substitutes for them. It can be seen that there is a match for steam from the biomass incinerator to the pharmaceutical plant and organic waste from the pharmaceutical plant to the biomass incinerator. Note that the addition "substitute natural gas" indicates that the demand would substitute for the input "natural gas". It is important to define possible substitutes for each plant type, as what can be substituted by what often differs from plant to plant.

\begin{tabular}{|c|c|c|c|c|c|c|}
\hline & & \multicolumn{4}{|c|}{$\begin{array}{l}\text { 1:Pharmaceutical } \\
\text { plant }\end{array}$} & \multirow{2}{*}{\begin{tabular}{|l|}
$\begin{array}{l}\text { 2:Biomass } \\
\text { incinerator }\end{array}$ \\
$\begin{array}{l}\text { 5d:Organic } \\
\text { waste }\end{array}$ \\
\end{tabular}} \\
\hline & & 1d:Water & $\begin{array}{l}\text { 2d:Natur } \\
\text { al gas }\end{array}$ & $\begin{array}{l}\text { 3d:Steam } \\
\text { (substitute } \\
\text { natural gas) }\end{array}$ & $\begin{array}{l}\text { 4d:Methane } \\
\text { (substitute } \\
\text { natural gas) }\end{array}$ & \\
\hline \multirow[t]{2}{*}{$\begin{array}{l}\text { 1:Pharmaceutical } \\
\text { plant }\end{array}$} & $\begin{array}{l}\text { 1s:Waste } \\
\text { water }\end{array}$ & & & & & \\
\hline & $\begin{array}{l}\text { 2s:Organi } \\
\text { c waste }\end{array}$ & & & & & Identical \\
\hline \multirow{2}{*}{$\begin{array}{l}\text { 2:Biomass } \\
\text { incinerator }\end{array}$} & 3s:Steam & & & Identical & & \\
\hline & 4s:Residue & & & & & \\
\hline
\end{tabular}

Fig.7: Part of the potential symbiosis DSM for the fictive industrial park

Each of the resource supplies and resource demands has a quantity. The amount of supply matching a demand cannot exceed the available supply. Furthermore, the amount of supply matching a demand cannot exceed the total demand. These two constraints can be formulated as

$$
S_{i} \geq \sum_{j=1}^{n} s_{i j}
$$

where $s_{i j}$ is a supply $i$ that meets a demand $j$. The sum of $s_{i j}$ cannot exceed the total available supply $S_{i}$. 


$$
D_{j} \geq \sum_{i=1}^{m} c_{i} s_{i j}
$$

Furthermore, the sum of supplies $s_{i j}$ for a demand $D_{j}$ has to be equal or less than the demand. $c_{i}$ is a conversion factor for treating up- and downstream substitutes. For example, if the demand is steam, either steam is supplied directly, in which case $c_{i}$ would be 1 , or indirectly, e.g. by burning methane in a boiler. For methane, $c_{i}$ would be the ratio of a unit of steam produced per unit of methane. By using conversion factors, upstream flows can be converted into downstream flows. Conversion factors allow for calculating the total amount of new resources that are substituted.

Three criteria are used for evaluating the symbiosis networks:

- $\quad$ Maximize the quantity of substituted new resources $s_{i j}$.

- Maximize net profit, simplified as revenue $r_{i j k}$ minus operating cost $o_{i j}$ for a match $s_{i j}$.

- Minimize capital investments $C_{i j}$ for a technology to transfer $s_{i j}$. (Pipeline for transmitting steam: $1 \mathrm{M} \$ / \mathrm{km} ; \$ 100,000$ per truck transporting $20 \mathrm{t}$ of organic waste)

Here, we have a simple case with only one technology option for transmitting energy or transporting material. The distances between plants are estimated by calculating a distance matrix from the plants' coordinates. Note that these are only examples for objective functions and we can easily imagine alternatives to these given. For example, we could separate between energy substituted and material substituted. Another way would be to calculate the equivalent of reduction in $\mathrm{CO} 2$ emission.

The supply / demand allocation problem in this case can be formulated as the multiobjective optimization problem with the objective functions

$$
\begin{gathered}
\sum_{i=1}^{m} \sum_{j=1}^{n} c_{i} s_{i j}=\max ! \\
\sum_{j=1}^{n} \sum_{i=1}^{m}\left(r_{i j}-o_{i j}\right)=\max ! \\
\sum_{i=1}^{m} \sum_{j=1}^{n} C_{i j}=\min !
\end{gathered}
$$

subject to the constraints:

$$
\begin{gathered}
\sum_{j=1}^{n} s_{i j}-S_{i} \leq 0 \\
\sum_{i=1}^{m} c_{i} s_{i j}-D_{j} \leq 0
\end{gathered}
$$

and

$$
s_{i j} \geq 0
$$


The problem is solved by using a multi-objective genetic algorithm (MOGA). MOGA is chosen, as it is scalable and leaves the possibility open for using non-linear objective functions and constraints. Non-linearity may come into play with economy-of-scale effects and discounts on resource flows. Table 2 shows the properties of a sample Paretooptimal symbiosis network. Note that it would not have been possible to detect the steam symbioses with an input / output matching alone as steam is generating within the pharmaceutical plant.

Table 2: Set of symbioses for optimal symbiosis network

\begin{tabular}{|l|l|l|}
\hline Supplier - receiver & Resource & Quantity [t/a] \\
\hline Toxic waste incinerator - refinery & Steam & 200,000 \\
\hline Pharmaceutical plant - biomass incinerator & Organic waste & 50,000 \\
\hline Biomass incinerator - refinery & Steam & 280,000 \\
\hline
\end{tabular}

The objective function vector for this symbiosis network is depicted in Table 3 . The resource savings are considerable. The main resource saved is steam, which is a means for transporting energy. It can be seen that the capital investments could be paid back by the net profit after one to two years. Note that for a more elaborate economic model, net present value (NPV) should be used for discounting future cash flows.

Table 3: Values for the objective function for the optimal symbiosis network

\begin{tabular}{|l|l|}
\hline Objective functions & $\begin{array}{l}\text { Values for a sample Pareto-optimal } \\
\text { symbiosis network }\end{array}$ \\
\hline New resources $s_{i j}$ substituted (steam, biomass) & $530,000 \mathrm{t} / \mathrm{a}$ \\
\hline Net profit $r_{i j}-o_{i j}$ & $2.5 \mathrm{M} \$$ \\
\hline Capital investments $C_{i j}$ & $4.5 \mathrm{M} \$$ \\
\hline
\end{tabular}

Note that in reality each individual symbiosis has to be economically feasible. This condition can be represented by additional constraints, for example, a positive NPV for each symbiosis.

\section{Conclusions}

This paper presents a modeling approach for industrial symbioses, based on DSMs in order to facilitate the identification of feasible symbioses. The modeling approach extends the existing input - output matching approaches by including different types of resource substitutions. It is demonstrated that the modeling approach can be used for identifying potential symbioses and searching for optimal symbiosis networks. It is furthermore demonstrated that the approach is capable of finding symbiosis opportunities that would not be found by an input - output matching approach alone. Future work aims at including symbiosis infrastructure technologies that are able to convert resources. Taking conversion into account would open up the possibility for finding further symbiosis opportunities. Finally, the ultimate objective of this work is to support the creation of industrial symbioses in reality, thereby increasing the competitiveness and sustainability of industry. 


\section{Acknowledgements}

The authors gratefully acknowledge the generous support by the following French and international industrial actors: Air Liquide, TOTAL, and EDF R\&D.

\section{References}

Andrei, O., 2008. A Rewriting Calculus for Graphs: Applications to Biology and Autonomous Systems. Institut National Polytechnique de Lorraine-INPL.

Andrei, O., Kirchner, H., 2008. A rewriting calculus for multigraphs with ports. Electron. Notes Theor. Comput. Sci. 219, 6782.

Bondy, J.A., Murty, U.S.R., 1976. Graph theory with applications. Macmillan, London.

Bretto, A., Faisant, A., Hennecart, F., 2012. Eléments de théorie des graphes. Springer Verlag France.

Browning, T.R., 2001. Applying the design structure matrix to system decomposition and integration problems: a review and new directions. IEEE Trans. Eng. Manag. 48, 292-306.

Browning, T.R., Eppinger, S.D., 2002. Modeling impacts of process architecture on cost and schedule risk in product development. IEEE Trans. Eng. Manag. 49, 428-442.

Cao, Kai, Feng Xiao, \& Wan, H., 2009. Applying agent-based modeling to the evolution of eco-industrial systems. Ecol. Econ. $68,2868-2876$.

Chertow, M.R., 2000. Industrial symbiosis: Literature and taxonomy. Annu. Rev. Energy Environ. 25, 313-337.

Chertow, M. R., Lombardi, D.R., 2005. Quantifying economic and environmental benefits of co-located firms. Environ. Sci. Technol. 39, 6535-6541.

Deutz, P., 2014. Food for Thought: Seeking the Essence of Industrial Symbiosis, in: Pathways to Environmental Sustainability. p. pp 3-11.

Gu, C., Leveneur, S., Estel, L., Yassine, A., 2013. Modeling and optimization of material/energy flow exchanges in an ecoindustrial park. Energy Procedia 36, 243-252.

Haberl, H., 2001. The energetic metabolism of societies part I: accounting concepts. J. Ind. Ecol.

Hein, A.M., 2014. How to Assess Heritage Systems in the Early Phases?, in: 6th International Systems \& Concurrent Engineering for Space Applications Conference. Weihingen, Germany.

Hein, A.M., Metsker, Y., Sturm, J., 2014. Towards a Capability Framework for Systems Architecting and Technology Strategy, in: Proceedings of the 16th International DSM ConferenceParis, Paris, France, 2-4 Juli 2014.

Hein, A.M., Jankovic, M., Farel, R., Yannou, B., 2015. A Conceptual Framework for Eco-Industrial Parks, in: Proceedings of the ASME 2015 International Design Engineering Technical Conferences \& Computers and Information in Engineering Conference IDETC/CIE 2015. pp. 987-988.

Hein, A.M., Pak, M., Pütz, D., Bühler, C., Reiss, P., 2012. World Ships-Architectures \& Feasibility Revisited. J. Br. Interplanet. Soc. 65, 119-133.

Hirtz, J., Stone, R. B., McAdams, D. A., Szykman, S., \& Wood, K.L., 2002. A functional basis for engineering design: reconciling and evolving previous efforts. Res. Eng. Des. 13, 65-82.

Hodge, M., Ochsendorf, J., Fernández, J., 2010. Quantifying potential profit from material recycling: A case study in brick manufacturing. J. Clean. Prod. 18, 1190-1199.

Jacobsen, N.B., 2006. Industrial Symbiosis in Kalundborg, Denmark: A Quantitative Assessment of Economic and Environmental Aspects. J. Ind. Ecol. 10, 239-255.

Kim, S.H., Yoon, S.G., Chae, S.H., Park, S., 2010. Economic and environmental optimization of a multi-site utility network for an industrial complex. J. Environ. Manage. 91, 690-705.

Korhonen, J., Snäkin, J.P., 2005. Analysing the evolution of industrial ecosystems: Concepts and application. Ecol. Econ. 52, $169-186$.

Leontief, W., 1986. Input-Output Economics.

Leontief, W., 1970. Environmental repercussions and the economic structure: an input-output approach. Rev. Econ. Stat.

Lowe, E.A., 2001. Eco-industrial park handbook for Asian developing countries.

Maillé, M., \& Frayret, J.M., 2013. Industrial By-Product Reuse and Synergy Optimization.

Monteiro, J.G.M.S., Silva, P.A.C., Araújo, O.Q.F., Medeiros, J.L., 2010. Pareto optimization of an industrial ecosystem: Sustainability maximization. Brazilian J. Chem. Eng. 27, 429-440.

Otto, K., Wood, K., 2000. Product Design: Techniques In Reverse Engineering And New Product Development Author: Kevin Otto, Kristin Wood, Publisher. Prentice Hall.

Pahl, G., Beitz, W., Feldhusen, J., Grote, K., 2007. Engineering design: a systematic approach.

Pektaş, Ş.T., Pultar, M., 2009. Modelling detailed information flows in building design with the parameter-based design structure matrix. Des. Stud. 27, 99-122.

Schulze, F., 2014. Classification and development of mathematical models and simulation for industrial ecology. University of Rhode Island.

Sokka, L., 2011. Local systems, global impacts : Using life cycle assessment to analyse the potential and constraints of industrial symbioses. VTT Publ. 1-158.

Stone, R. B., \& Wood, K.L., 2000. Development of a functional basis for design. J. Mech. Des. 122, 359-370.

Tian, J., Zelkowitz, M. V., 1992. A formal program complexity model and its application. J. Syst. Softw. 